\title{
Modeling of Finned-Tube Evaporator using Pure and Zeotropic Blend Refrigerants
}

\author{
By Ali Hussain Tarrad ${ }^{*}$ \\ Ayad Khudhair Al-Nadawi ${ }^{\dagger}$
}

\begin{abstract}
The present research represents a mathematical model applied for a louvered finned tube evaporator. The steady state experimental data of a window type (2) ton of refrigeration air conditioning unit was used to build a tube by tube model to investigate the evaporator performance. The refrigerants selected for this object were $R-22$ and the zeotropic blends $R-407 C$ and $R-407 A$ refrigerants. The validation of the present model for pure and mixtures showed good agreement between experimental and those predicted values. The maximum scatter between experimental and predicted evaporator duty was within (-7 to 1) \% for all of the simulated refrigerants. The predicted evaporator exit air temperature showed a higher scatter. They were within $(-25$ to +12$) \%$ for all of the simulated refrigerants for the ambient dry bulb temperature range of $(28-38)^{\circ} \mathrm{C}$.
\end{abstract}

Keywords: Finned Tube, Evaporator, Refrigerant Alternatives, Zeotropic Blends, Heat Exchangers

\section{Introduction}

The modeling of finned tube evaporator is a daunting task for traditional exhaustive search techniques. This is because of the complexity of the twophase flow and heat exchanged process between the refrigerant and the air stream, mass transfer of the condensate flow in the air side and the flow configuration.

Domanski and Didion (1983) reported a model for both of the evaporator and condenser based on tube-by-tube technique. A comparison of computer results against laboratory test data showed that the maximum discrepancy was $(3.4 \%)$ for cooling capacity. Domanski (1989) presented a computer model (EVSIM) for one-slab or two-slab evaporator for a given refrigerant enthalpy at the coil inlet, saturation temperature and superheated at the coil outlet. The verification of the model showed that the prediction of total capacities were within $(8.2 \%)$ of the test results.

Bensafi and Borg (1997) formulated a computational model for detailed design of finned-tube heat exchanger based on tube-by-tube technique. The condenser and evaporator were tested using water, R-22, R-134a and R407C. The Comparison with experimental tests showed discrepancies of $(\mp 5) \%$ on the coil duty. Domanski (1999) presented a finned-tube

\footnotetext{
*Assistant Professor, Denmark.

${ }^{\dagger}$ Assistant Lecturer, Al-Anbar Technical Institute, Iraq.
} 
evaporator model as a "tube-by-tube" scheme took into account a nonuniform air distribution. Simulation results were displayed for each tube on a side view of the heat exchanger identifying tube connection. Techarungpaisan et al. (2006) postulated a steady state simulation model to predict the performance of a small split type air conditioner with integrated water heater. The percentage deviations of the experimental values from the predicted value of the evaporator and condenser exit air temperature were $(4 \%)$ and $(3 \%)$ respectively.

A detailed design of finned tube evaporator heat exchanger coil in air conditioning unit was developed by Tarrad and Shehhab (2007). The evaporation and superheating portions of heat exchanger have been modeled separately to predict the exit air condition, dry bulb temperature and humidity content at the leaving section of the cooling coil. The evaporator mathematical model showed a well agreement with the experimental data of this research. Hassan et al. (2009) suggested a dynamic analysis for subcritical vapor compression system. The comparison between the experimental and theoretical model showed a good agreement with overall error of a bout (5\%).

Sarntichartsak and Kaewcholkram (2014) studied the effects of evaporator circuiting on the system performance of inverter air conditioner. Four evaporator configurations were tested using R22, R407C, R417A, R404A, and R507 using tube-by-tube and segment-by-segment modeling approach. The predicted values of capacities were agreed with the experimental data within the maximum error of 8 and $5 \%$ for tube-by-tube and segment-by-segment modeling approaches, respectively. Berger et al. (2014) presented a 1D heat exchanger model implemented in a domestic cooling cycle. This model based on a distributed parameter approach. The experimental validation has shown satisfactory agreement with the predicted model data.

In the present work a simulation model was built for rating objectives of finned tube evaporator used in air conditioning unit. It depends on the technique of performing a step by step solution following the flow of refrigerant in a tube by tube procedure. The model is capable to handle the prediction of the different parameters describing the heat transfer process for both sides of the evaporator.

\section{Model Background}

The tube-by-tube method is implemented to build up EVATBT program and evaluate the performance of a single finned tube evaporator. This method reduces the general finned coil to a single tube problem classified as steady state-distributed parameter model, Domanski and Didion (1983). There are two techniques to simulate the heat exchanger, forward and backward. In the forward technique, the selection of tube for performance evaluation is at the same direction as the refrigerant or air flow and the outputs are the outlet air and refrigerant parameters. The backward technique establishes its 
performance at the opposite direction of the refrigerant or air flow. The configuration of heat exchanger circuit will control the way that may be used to model the heat exchangers.

\section{Evaporator Structure}

The evaporator consists of four rows and three circuits. Figure 1 shows the circuit arrangement and flow directions. The entrance of the refrigerant of the first two circuits is at the first row and for the third circuit; the refrigerant enters the evaporator at the second row. Obviously, the circuit arrangement imposes the forward technique for both refrigerant and air side.

The characteristics and physical dimensions of the tested evaporator by AlNadawi (2010) are shown in table 1. It is a part of the window type air conditioning unit available commercially in the local market.

Figure 1. Evaporator configuration, Al-Nadawi (2010).

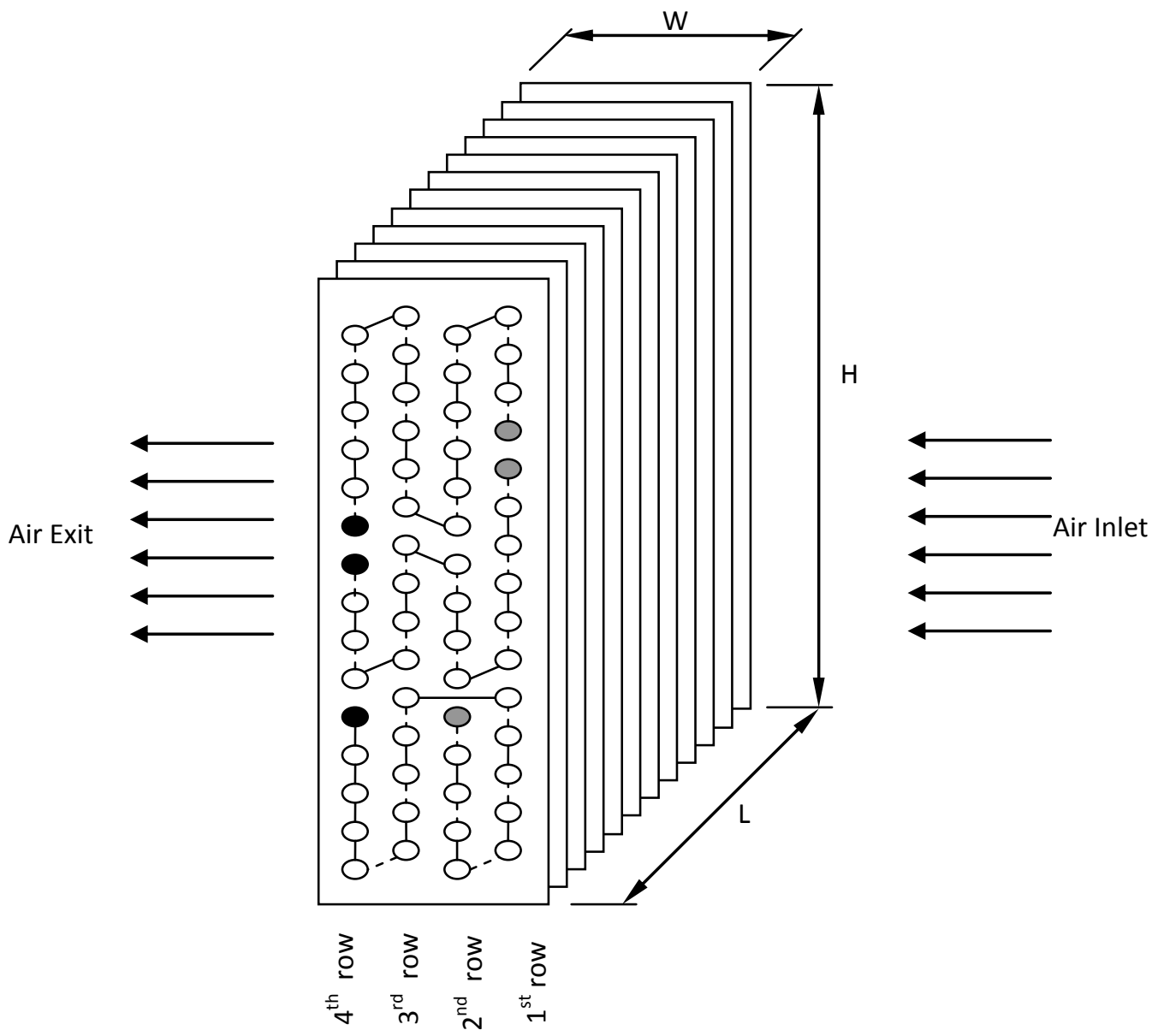

Model Technique

The important part of the computer model is the assigned tube for simulation. The following describes the model analyzing procedure: 
$\underline{\text { Air Side }}$

At the beginning, the temperature of air is known only at the first depth row of the heat exchanger and is estimated for the other row.

1. If the refrigerant enters the heat exchanger and runs continuously to the second row without any jump to the other rows, then the temperature of air at the first depth row is used to find out the temperature and humidity ratio for each tube at the outlet of the first depth row. Then, the mean value of temperature and humidity ratio is taken and used as input to the second row and kept on to the end of the third row.

2. In a circuit which incorporates an inlet of refrigerants at a row which is far away from the first row, here the dry bulb temperature of air must be guessed and checked for converging which adds more complex iteration loop to the computer model.

Table 1. The Characteristic Dimensions of the Test Evaporator

\begin{tabular}{|l|c|}
\hline \multicolumn{1}{|c|}{ Dimension Specification } & Evaporator \\
\hline Tube Length $(\mathrm{mm})$ & 380 \\
\hline Dimension $(\mathrm{L} \times \mathrm{W} \times \mathrm{H})(\mathrm{mm})$ & $380 \times 90 \times 380$ \\
\hline No. of Circuits & 3 \\
\hline No. of Rows & 4 \\
\hline Tube outside diameter $(\mathrm{mm})$ & 9.5 \\
\hline Tube inside diameter $(\mathrm{mm})$ & 7.8994 \\
\hline Tube metal & Copper \\
\hline Tube Metal Thermal conductivity $(\mathrm{W} / \mathrm{m} . \mathrm{K})$ & 386 \\
\hline Inner Tube Surface & Smooth \\
\hline Transverse tube pitch $(\mathrm{mm})$ & 22.3 \\
\hline Longitudinal tube pitch $(\mathrm{mm})$ & 22.3 \\
\hline Fin thickness $(\mathrm{mm})$ & 0.235 \\
\hline Fin pitch $(\mathrm{mm})$ & 2 \\
\hline Total No. of fins & 174 \\
\hline Fin type & Louvered \\
\hline Fin metal & Aluminum \\
\hline Fin Thermal Conductivity $(\mathrm{W} / \mathrm{m} . \mathrm{K})$ & 202 \\
\hline Area of heat exchanger $\left(\mathrm{m}^{2}\right)$ & 11.12 \\
\hline Area of fin $\left(\mathrm{m}^{2}\right)$ & 10.4 \\
\hline Area of tube $\left(\mathrm{m}^{2}\right)$ & 0.715 \\
\hline
\end{tabular}




\section{$\underline{\text { Refrigerant Side }}$}

The refrigerant travels in the tube regardless of the position wherever the entrance of the refrigerant to the circuit is. It should be noted that the pressure at the exit of each tube is unknown thus this pressure in the first tube is assumed. The assumed value is used to find out the refrigerant parameter such as the physical properties of refrigerant.

Calculation of the pressure drop of the tube is then accomplished and compared to the assumed pressure drop until convergence was achieved. Then the exit pressure is used as inlet pressure to the next tube and the same procedure is repeated until the whole heat exchanger is simulated.

Figure 2 shows the control volume of the tube and reveals the inlet and outlet parameter for the tube calculations. To find the quality of the refrigerant, a constant heat flux was assumed due to a small change of air temperature during operation and hence the quality varies linearly through the heat exchanger, Kempiak and Craw (1991).

Figure 2. Control Volume of an Individual Tube, Al-Nadawi (2010)

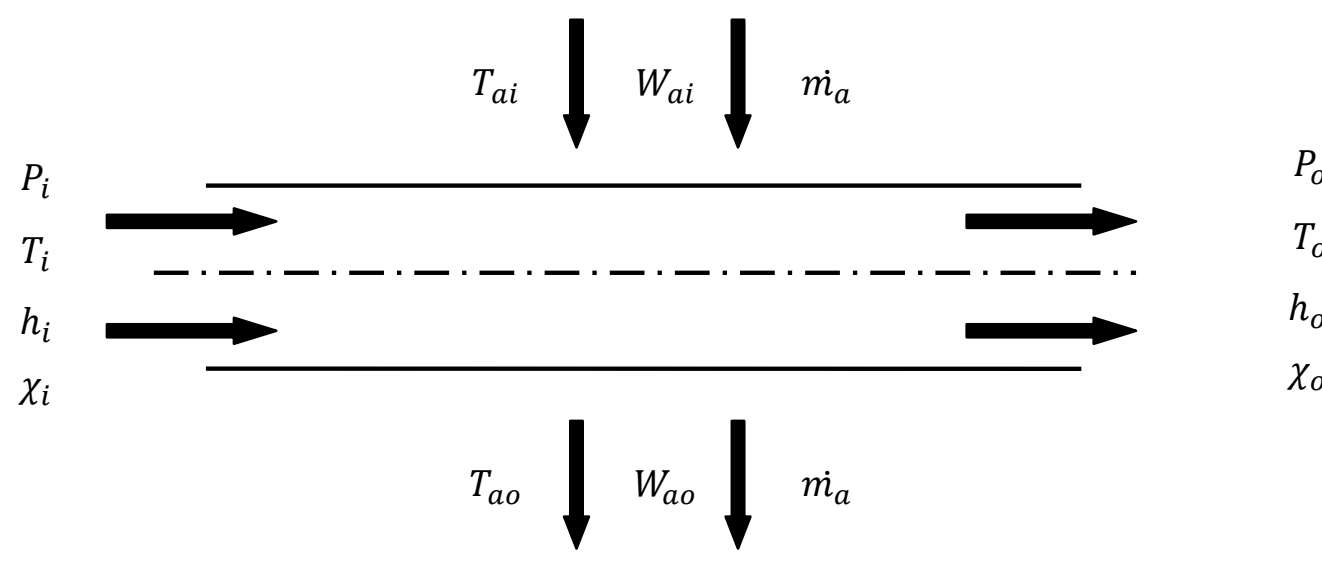

\section{Continuity Equation}

The conversation of mass principle of control volume can be expressed as:

$\frac{d}{d t} \int_{C V} \rho d V+\int_{C S} \rho(\vec{V} \cdot \vec{n}) d A=0$

Splitting the surface integral in the above equation into two parts-one for the outgoing flow stream (positive) and one for the incoming streams (negative) then the general conversation of mass relation can be expressed as:

$\frac{d}{d t} \int_{C V} \rho d V+\sum_{\text {out }} \rho V_{n} d A-\sum_{\text {in }} \rho V_{n} d A=0$

The parameter (A) represents the cross sectional area of the flow conduit. Equation (2) can be expressed as

$\frac{d}{d t} \int_{C V} \rho d V=\sum_{\text {in }} \dot{m}-\sum_{\text {out }} \dot{m}$ 
Or

$\frac{d m_{C V}}{d t}=\sum_{\text {in }} \dot{m}-\sum_{o u t} \dot{m}$

For steady flow process through the heat exchangers so equation (4) would be:

$\sum_{\text {in }} \dot{m}=\sum_{\text {out }} \dot{m}$

\section{Energy Equation}

The energy equation for a fixed control volume can be expressed by:

$\dot{Q}_{n e t, i n}+\dot{W}_{\text {shaft,net in }}=\frac{d}{d t} \int_{C V} e \rho d \mho+\sum_{\text {out }} \dot{m}\left(h+\frac{V^{2}}{2}+g z\right)-\sum_{\text {in }} \dot{m}\left(h+\frac{V^{2}}{2}+g z\right)$

For steady state flow, $\frac{d}{d t} \int_{C V} e \rho d \mho=0$, and typically heat exchangers involve no work interaction and negligible kinetic and potential energy change $\left(\frac{V^{2}}{2}=\right.$ $g z=0$. The term $e=u+V 22+g z$, is the total energy per unit mass.

Rearranging and substituting in (6),

$\dot{Q}_{\text {net }, \text { in }}=\sum_{\text {out }} \dot{m} h-\sum_{\text {in }} \dot{m} h$

Then the final expressions of general formulae for the mass conservation and energy balance, (5) and (7) respectively were implemented in the present rating model.

\section{Refrigerant Side Heat Transfer}

\section{Single Phase}

Single phase forced convection takes place at outlet of the evaporator, as a superheated vapor. The heat transfer coefficient of the single phase in the superheated region for all of the refrigerants can be calculated by the correlation of Kay \& London cited in Stewart (2003):

$$
\text { St } \operatorname{Pr}^{2 / 3}=a_{\text {st }} \operatorname{Re}_{\text {Di }}^{b_{\text {st }}}
$$

Where the coefficients $\left(a_{\mathrm{st}}\right)$ and $\left(\mathrm{b}_{\mathrm{st}}\right)$ are constants, their numerical values are stated according to the flow regime of refrigerant.

And

Flow Boiling

$$
\mathrm{St}=\frac{\mathrm{Nu}_{\mathrm{D}}}{\mathrm{Re}_{\mathrm{Di}} \mathrm{Pr}}=\frac{\bar{\alpha}}{\mathrm{GCp}} \ldots \ldots
$$

The expression for pure R-22 heat transfer coefficient is taken from Tong (1965) cited in Sadler (2000) expressed as: 


$$
\propto=(0.018687) \frac{\mathrm{k}_{1}}{\mathrm{D}^{0.2}}\left(\frac{\mathrm{G}}{\mu_{\mathrm{l}}}\right)^{0.8}\left(\frac{\mu_{1} \mathrm{Cp}}{\mathrm{k}_{\mathrm{l}}}\right)^{0.4}\left(\frac{\rho_{\mathrm{l}}}{\rho_{\mathrm{g}}}\right)^{0.375}\left(\frac{\mu_{\mathrm{g}}}{\mu_{\mathrm{l}}}\right)^{0.075}\left(\frac{\chi_{\mathrm{e}}-\chi_{\mathrm{i}}}{\chi_{\mathrm{e}}^{0.325}-\chi_{\mathrm{i}}{ }^{0.325}}\right)
$$

For R407C and R407A, the modified Jung and Wattelet correlation is a good choice. This formula was suggested by Bivens and Yokozeki for the refrigerants R-32/R-125 and R-32/R-125/R-134a. It has been used to account for the mass transfer, Radermacher and Hwang (2005) as:

Where

$$
\propto=\frac{\alpha_{\mathrm{tf}}}{1+\alpha_{\mathrm{tf}} \frac{\mathrm{T}_{\text {int }}}{\mathrm{q}}} \ldots \ldots(11 . \mathrm{a})
$$

$$
\begin{aligned}
& \mathrm{T}_{\text {int }}=0.175\left(\mathrm{~T}_{\mathrm{d}}-\mathrm{T}_{\mathrm{b}}\right)\left\{1-\mathrm{e}^{\left(-\frac{\mathrm{q}}{1.3 \times 10^{-4} \mathrm{\rho}_{\mathrm{l}} \mathrm{h}_{\mathrm{fg}}}\right)}\right\} \ldots \ldots \\
& \propto_{\mathrm{tf}}=\left[\propto_{\mathrm{nb}}{ }^{2.5}+\propto_{\mathrm{bc}}{ }^{2.5}\right]^{1 / 2.5} \ldots \ldots \text { (11.c) } \\
& \propto_{\mathrm{nb}}=55 \mathrm{M}^{-0.5} \mathrm{q}^{0.67} \mathrm{P}_{\mathrm{r}}^{0.12}\left(-\log _{10} \mathrm{P}_{\mathrm{r}}\right)^{-0.55} \\
& \propto_{\mathrm{bc}}=\mathrm{F} \propto_{\mathrm{l}} \mathrm{R} \ldots \ldots(15) \\
& \mathrm{F}=\left(0.29+\frac{1}{\mathrm{X}_{\mathrm{tt}}}\right)^{0.85} \ldots \ldots(11 . \mathrm{e}) \\
& \mathrm{X}_{\mathrm{tt}}=\left(\frac{1-\chi}{\chi}\right)^{0.875}\left(\frac{\mu_{\mathrm{l}}}{\mu_{\mathrm{g}}}\right)^{0.125}\left(\frac{\rho_{\mathrm{g}}}{\rho_{\mathrm{l}}}\right)^{0.5} \ldots . .(11 . \mathrm{f}) \\
& \mathrm{R}=2.83 \mathrm{Fr}_{1}{ }^{0.2} \text { if } \mathrm{Fr}_{1} \leq 0.25 \text { and } \mathrm{R}=2.15 \text { if } \mathrm{Fr}_{1}>0.25
\end{aligned}
$$

Here $\left(\mathrm{Fr}_{1}\right)$ is defined by $\left(\frac{\mathrm{G}^{2}}{\rho_{\mathrm{l}}{ }^{2} \mathrm{gD}}\right)$ and $\left(\alpha_{\mathrm{l}}\right)$ is the single-phase liquid heat transfer coefficient as estimated by Dittus-Bolter correlation.

\section{Pressure Drop}

The pressure drop composes of three components, gravitational, momentum and frictional pressure drop which represent the potential energy, kinetic energy of the fluid and that due to friction on the channel wall, so:

$$
\Delta \mathrm{P}_{\text {total }}=\Delta \mathrm{P}_{\text {static }}+\Delta \mathrm{P}_{\text {momentum }}+\Delta \mathrm{P}_{\text {friction }}
$$

For horizontal tube, $\Delta \mathrm{P}_{\text {static }}=0$, therefore only pressure drop due to momentum and friction will be considered with distinction between two phase and single phase flow.

\section{Single-Phase}

Frictional pressure drop can be calculated using the fanning equation with the fanning friction factor, Domanski and Didion (1983), as follows:

$$
\begin{gathered}
\Delta \mathrm{P}=\frac{2 \mathrm{f} \mathrm{G}^{2} \mathrm{~L}}{\mathrm{D}_{\mathrm{i} \rho} \rho} \ldots \ldots(13 . \mathrm{a}) \\
\mathrm{f}=0.046 \mathrm{R}_{\mathrm{e}}^{-0.2} \ldots \ldots(13 . \mathrm{b})
\end{gathered}
$$

Pressure drop due to momentum change can be calculated, as follows:

$$
\frac{\mathrm{dP}}{\mathrm{dL}}=-\mathrm{G}^{2} \frac{\mathrm{d} v}{\mathrm{dL}}
$$




\section{Two-Phase}

The momentum pressure drop reflects the change in kinetic energy of the flow and is given by:

$$
\Delta \mathrm{P}_{\mathrm{mom}}=\frac{16 \mathrm{~m}^{2}}{\pi^{2} \mathrm{D}^{4}}\left\{\left[\frac{\chi_{\mathrm{o}}{ }^{2}}{\rho_{\mathrm{g}} \epsilon_{\mathrm{o}}}+\frac{\left(1-\chi_{\mathrm{o}}\right)^{2}}{\rho_{\mathrm{l}}\left(1-\epsilon_{\mathrm{o}}\right)}\right]-\left[\frac{\chi_{\mathrm{i}}{ }^{2}}{\rho_{\mathrm{g}} \epsilon_{\mathrm{i}}}+\frac{\left(1-\chi_{\mathrm{i}}\right)^{2}}{\rho_{\mathrm{l}}\left(1-\epsilon_{\mathrm{i}}\right)}\right]\right\} \ldots . . \text { (15.a) }
$$

The void fraction $\epsilon$, can be predicted by using Zivi (1964) cited in Sweeney and Chato (1996).

$$
\epsilon=\frac{1}{1+\left(\frac{1-\chi}{\chi}\right)\left(\frac{\rho_{\mathrm{g}}}{\rho_{1}}\right)^{0.67} \ldots \ldots . .}
$$

For frictional pressure drop, one of the most accurate two-phase pressure drop correlations is used. A general formula based on optimized correlation for $\left(\phi_{\mathrm{fo}}^{2}\right)$ using a large data base of two-phase pressure drop measurement was presented by Quiben (2005). This model depends on the vapor quality and utilizes a two-phase multiplier as:

$$
\begin{gathered}
\Delta \mathrm{P}_{\text {friction }}=\Delta \mathrm{P}_{\mathrm{Lo}} \phi_{\text {fo }}^{2} \ldots \ldots \\
\phi_{\text {fo }}^{2}=\mathrm{E}+\frac{3.24 \mathrm{~F} \mathrm{H}}{\mathrm{Fr}_{\mathrm{H}}^{0.045} \mathrm{We}_{\mathrm{L}}^{0.035}} \ldots \ldots .
\end{gathered}
$$

Where $\left(\mathrm{Fr}_{\mathrm{h}}\right),(\mathrm{E}),(\mathrm{F})$ and $(\mathrm{H})$ are, as follows:

$$
\begin{gathered}
\mathrm{Fr}_{\mathrm{H}}=\frac{\mathrm{G}^{2}}{\mathrm{gD} \rho_{\mathrm{h}}^{2}} \ldots \ldots(16 . \mathrm{c}) \\
\mathrm{E}=(1-\chi)^{2}+\chi^{2} \frac{\rho_{\mathrm{f}} \mathrm{f}_{\mathrm{Go}}}{\rho_{\mathrm{g}} \mathrm{f}_{\mathrm{Lo}}} \ldots \ldots(16 . \mathrm{d}) \\
\mathrm{f}_{\mathrm{Lo}}=\frac{0.079}{\mathrm{Re}_{\mathrm{Lo}}^{0.25}} \ldots \ldots(16 . \mathrm{e}) \\
\mathrm{f}_{\mathrm{Go}}=\frac{0.079}{\mathrm{Re}_{\mathrm{Go}}^{0.25}} \ldots \ldots(16 . \mathrm{f}) \\
\mathrm{F}=\chi^{0.78}(1-\chi)^{0.224} \ldots \ldots(16 . \mathrm{g}) \\
\mathrm{H}=\left(\frac{\rho_{\mathrm{l}}}{\rho_{\mathrm{g}}}\right)^{0.91}\left(\frac{\mu_{\mathrm{g}}}{\mu_{\mathrm{l}}}\right)^{0.19}\left(1-\frac{\mu_{\mathrm{g}}}{\mu_{\mathrm{l}}}\right)^{0.7} \ldots \ldots(
\end{gathered}
$$

Liquid Weber number $\left(\mathrm{We}_{\mathrm{L}}\right)$, is defined as:

$$
\begin{gathered}
\mathrm{We}_{\mathrm{L}}=\frac{\mathrm{G}^{2} \mathrm{D}}{\sigma \rho_{\mathrm{h}}} \ldots \ldots(17 . \mathrm{a}) \\
\rho_{\mathrm{h}}=\left(\frac{\chi}{\rho_{\mathrm{g}}}+\frac{1-\chi}{\rho_{\mathrm{l}}}\right)^{-1} \ldots \ldots(17.6)
\end{gathered}
$$

In the above correlation, the value of $(\chi)$ is considered to be a mean value between the entering and exiting sides of the tube in the form: $\chi=\frac{\chi_{i}+\chi_{0}}{2}$

The above correlation is used only for R-22, but for R-407C and R-407A, the new correlation developed by Choi et al. (1999) is used. This correlation was developed depending on a data base composing of the refrigerants; R-125, R134a, R-32, R-410A, R-22, R-407C and R-32/R-134a (25/75\% mass). The correlation predicted the pressure drop in smooth tube with an average residual of $(15 \%)$. The modified correlation expressed as:

$$
\Delta \mathrm{P}=\Delta \mathrm{P}_{\text {friction }}+\Delta \mathrm{P}_{\text {acceleration }}=\left\{\frac{\mathrm{f}_{\mathrm{N}} \mathrm{L}\left(\mathrm{v}_{\text {out }}-\mathrm{v}_{\text {in }}\right)}{\mathrm{D}}+\left(\mathrm{v}_{\text {out }}-\mathrm{v}_{\text {in }}\right)\right\} \mathrm{G}^{2} \ldots \text { (18.a) }
$$


Specific volumes of the two-phase fluid are obtained from a linear quality weighted sum of the vapor and liquid specific volumes at either the outlet or inlet of the tube. The new two-phase friction factor is:

$$
\mathrm{f}_{\mathrm{N}}=0.00506 \mathrm{R}_{\mathrm{e}_{\mathrm{fo}}}^{-0.0951} \mathrm{~K}_{\mathrm{f}}^{0.1554} \ldots \ldots \text { (18.b) }
$$

The friction factor is based on the liquid Reynolds number and the two-phase number:

$$
\mathrm{K}_{\mathrm{f}}=\frac{\Delta \mathrm{X} \mathrm{h}_{\mathrm{fg}}}{\mathrm{Lg}}
$$

\section{Air Side}

\section{Air Side Surface Efficiency}

For enhanced fin geometry, louvered or slit fins, the present work uses the Schmidt's circular fin approximation analysis which overestimates the fin efficiency by up to (5\%), Stewart (2003). For a plate fin, Schmidt (1945) suggested that the plate fin can be divided into hexagonal shape fin, as shown in Figure 3.

Figure 3. Staggered tube configuration, Stewart (2003).

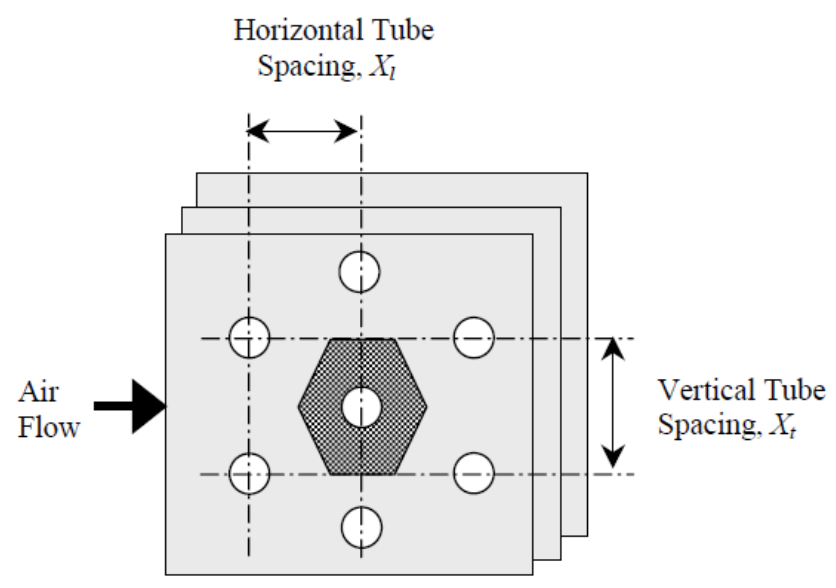

Then, he analyzed hexagonal fin and concluded that they can be treated as circular fin by replacing the outer radius of the fin with the equivalent radius. The empirical relation for the equivalent radius is given by:

$$
\frac{r_{\mathrm{e}}}{\mathrm{r}_{\mathrm{t}}}=1.27 \Psi(\beta-0.3)^{\frac{1}{2}}
$$

Where $\left(\mathrm{r}_{\mathrm{t}}\right)$ is the outside radius. The coefficients $(\Psi)$ and $(\beta)$ are defined as:

$$
\Psi=\frac{B}{r_{t}} \quad \text { and } \quad \beta=\frac{H}{B}
$$

For the present analysis, $\mathrm{B}=\mathrm{X}_{\mathrm{L}}$ if $\mathrm{X}_{1}<\mathrm{X}_{\mathrm{t}} / 2$, otherwise $\mathrm{B}=\mathrm{X}_{\mathrm{t}} / 2$

$$
\mathrm{H}=\frac{1}{2} \sqrt{\left(\frac{\mathrm{X}_{\mathrm{t}}}{2}\right)^{2}+\mathrm{X}_{\mathrm{l}}^{2}}
$$

The length of fin is much greater than the thickness so the parameter $(\mathrm{m})$ is:

$$
\mathrm{m}=\left(\frac{2 \alpha_{\mathrm{a}}}{\mathrm{k}_{\mathrm{f}} \mathrm{t}_{\mathrm{f}}}\right)^{\frac{1}{2}} \ldots \ldots
$$


The fin efficiency parameter can be defined as:

$$
\Phi=\left(\frac{r_{e}}{r_{t}}-1\right)\left(1+0.35 \ln \left(\frac{r_{e}}{r_{t}}\right)\right) \ldots . .(19 . c)
$$

The fin efficiency is defined as a function of $\left(\Phi, \mathrm{m}, \mathrm{r}_{\mathrm{t}}\right)$

$$
\eta_{\mathrm{f}}=\frac{\tanh \left(\mathrm{m} r_{\mathrm{t}} \Phi\right)}{\mathrm{m} \mathrm{r}_{\mathrm{t}} \Phi}
$$

The total surface efficiency is given by:

$$
\eta_{\mathrm{s}}=1-\frac{\mathrm{A}_{\mathrm{f}}}{\mathrm{A}_{\mathrm{o}}}\left(1-\eta_{\mathrm{f}}\right)
$$

The fin area and total area are given by:

$$
\begin{array}{r}
A_{f}=\left[(W \times H)-\left(\frac{\pi}{4} D_{o}^{2}\right)\right] \times 2 \times n_{f} \\
A_{t}=\left(\pi D_{o} L\right)-\left(\pi D_{o} n_{f} t_{f}\right) \ldots \ldots \\
A_{o}=A_{f}+A_{t} \ldots \ldots(19 . h)
\end{array}
$$

\section{Air Side Heat Transfer Coefficient}

For louvered fin Wang correlation, cited in Stewart (2003), is applied to determine the Colburne $\mathrm{j}$ - factor which is associated with heat transfer coefficient by:

$$
\overline{\alpha_{\mathrm{a}}}=\frac{\mathrm{jC}_{\mathrm{p}} \mathrm{G}_{\max }}{\mathrm{Pr}^{2 / 3}}
$$

Where $\left(G_{\max }\right)$ is the mass flux of the air through the minimum flow area $\left(\frac{m_{a}}{A_{\min }}\right)$. The specific heat in the above equation is replaced by the humid specific heat, taken as (1.022 $\left.\frac{\mathrm{kJ}}{\mathrm{kg} \cdot \mathrm{K}}\right)$ as suggested by Tarrad et al. (2008).

For the staggered tube arrangement, the minimum flow area is calculated using the relation cited in Subbarao (2008), as follows:

$$
A_{\min }=\left[\left(\left(\frac{L}{X_{t}}-1\right) \times C\right)+\left(\left(X_{t}-D_{o}\right) \times\left(1-\left(t_{f} \times n_{f}\right)\right)\right)\right] \times H \ldots(21 . a)
$$

Where $\mathrm{C}$ is such that:

$$
\begin{aligned}
& \mathrm{C}=2 \times \mathrm{a} \quad \text { if } 2 \times \mathrm{a}<2 \times \mathrm{b} \text { and } \mathrm{C}=2 \times \mathrm{b} \quad \text { if } 2 \times \mathrm{b}<2 \times \mathrm{a} \\
& \text { Here } \quad 2 \times a=\left(X_{t}-D_{o}\right) \times\left(1-t_{f} \times n_{f}\right) \ldots \ldots(21 . b) \\
& \mathrm{b}=\left[0.5 \times \mathrm{X}_{\mathrm{t}}^{2}\right]^{0.5}-\mathrm{D}_{\mathrm{o}}-\left(\mathrm{X}_{\mathrm{t}}-\mathrm{D}_{\mathrm{o}}\right) \times \mathrm{t}_{\mathrm{f}} \times \mathrm{n}_{\mathrm{f}} \ldots \ldots \text { (21.c) }
\end{aligned}
$$

The Colburne $\mathrm{j}$ - factor depends on the Reynolds number, full detailed method is cited by Al-Nadawi (2010).

\section{Overall Heat Transfer Coefficient}

By using the heat transfer coefficient of refrigerant and air with the inclusion of the surface fouling and fin effect, (Incropera and DeWitt, 1985), the overall heat transfer coefficient can be expressed as:

$$
\mathrm{UA}=\left\{\frac{1}{\left(\eta_{s} \alpha A\right)_{r}}+\frac{R_{f, r}^{\prime \prime}}{\left(\eta_{s} A\right)_{r}}+R_{w}+\frac{R_{f, a}^{\prime \prime}}{\left(\eta_{s} A\right)_{a}}+\frac{1}{\left(\eta_{s} \alpha A\right)_{a}}\right\}^{-1} \ldots \ldots
$$


The conductance resistance $\left(R_{w}\right)$ is obtained from $R_{w}=\frac{\ln \left(r_{o} / r_{i}\right)}{2 \pi k L}$. The fouling factors are assumed to be (0.0004) $\left(\frac{\mathrm{m}^{2} . \mathrm{K}}{\mathrm{W}}\right)(0.0002)\left(\frac{\mathrm{m}^{2} . \mathrm{K}}{\mathrm{W}}\right)$ and (0.0004) $\left(\frac{\mathrm{m}^{2} . \mathrm{K}}{\mathrm{W}}\right)$ for refrigerant vapor, liquid and air respectively, (Janna, 2000). Since there are no fins on the refrigerant side of the tubes, the refrigerants side efficiency is (1).

\section{Model Verification}

The experimental data obtained from a drop-in technique for alternatives to R-22 in a window type air conditioner unit having (2) ton of refrigeration were used for this object.

The simulated results of the present model, EVATBT program, showed an excellent agreement with the experimental data.

The predicted duties when circulating R-22 through the air conditioner were lower than those of the measured data, as shown in Figure 4. All of the calculated duties show an acceptable deviation and fall within (0 to -4$) \%$, where the deviation is defined as:

$$
\Phi^{\overline{+}}=\left(\Phi_{\text {theoretical }}-\Phi_{\text {experimental }}\right) / \Phi_{\text {experimental }} \ldots . . .(23)
$$

Figure 4. A Comparison for Experimental and Theoretical Evaporator Duties

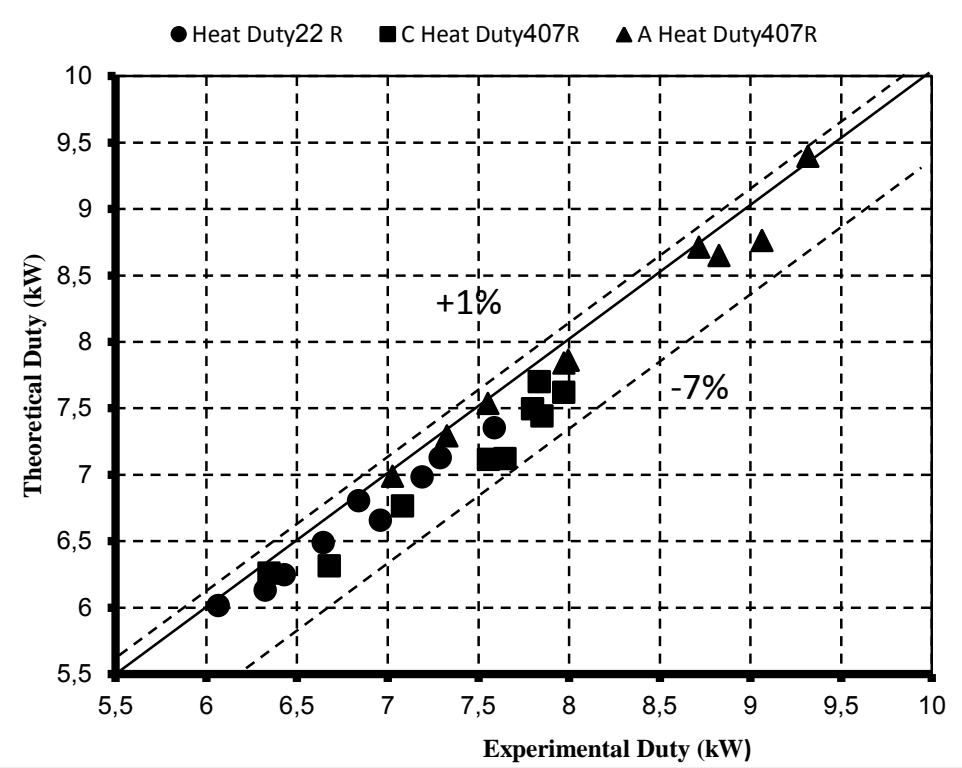

For R-407C, there is a scatter for the predicted duties and all of the experimental data lie under the predicted within (7) \%. The data when circulating R-407A revealed a little scatter. The maximum deviation range was between $(-3.3$ to 1$) \%$. It is obvious that the predicted heat duty fell within ( -7 to 1$) \%$ for all of the refrigerants in the operating air temperature range. 
The value of theoretical air temperature predicted by the EVATBT program is taken as a mean value of all of the estimated value from the tube outlet at the fourth row. Figure 5 shows a comparison between the experimental and theoretical predicted values for the different refrigerants handled in the present work. Most of the predicted air dry bulb temperature showed a scatter of discrepancy with respect to the experimental data within a value between (-25 to 12$) \%$. It is worthwhile to mention the following scatters for the air outlet temperature for the test entering air dry bulb temperature range (28 to $38)^{\circ} \mathrm{C}$ :

- When R-22 refrigerant is used, EVATBT program simulation shows that the maximum discrepancy of the evaporator outlet temperature is ( -25.4 to 10.2$) \%$.

- When R-407A is circulated, the maximum discrepancy in air temperature was found to be (-23.7 to 6.2) \% .

- When $\mathrm{R}-407 \mathrm{C}$ refrigerant is circulated the maximum discrepancy in air temperature simulation is (-23.5 to 12.3$) \%$.

Figure 5. A Comparison for Experimental and Theoretical Exit Air Dry Bulb Temperature through the Heat Exchanger

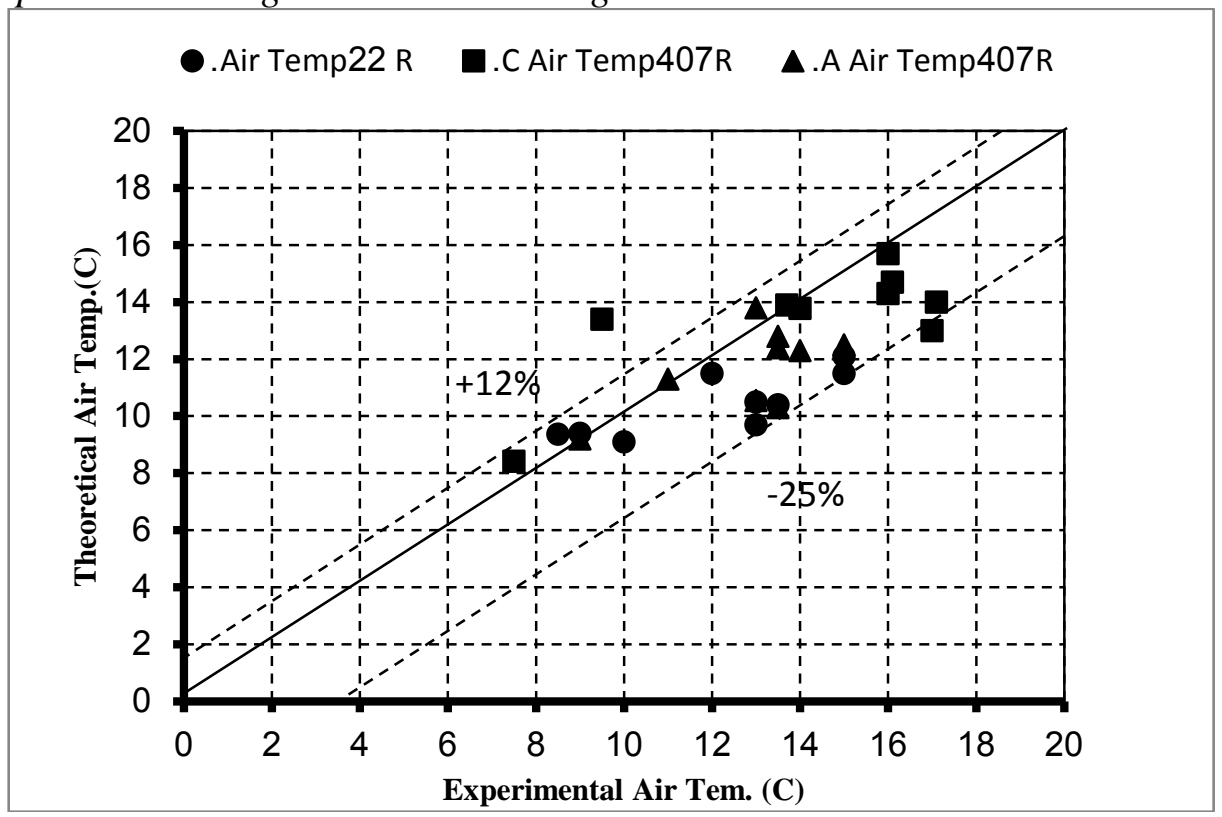

\section{Visual Representation}

\section{Cooling Load Distribution}

Figure (6) shows the load distribution for each tube of the evaporator. In general, for R-22 the circuit number two shows the highest cooling load for tube followed by circuit number three and finally circuit number one. In the first circuit, the cooling capacity of the first tube, tube number (1), is equal to (140) W, while the second circuit begins with (171.3) W at the first tube, tube 
number (23). The third circuit shows a value which lies between circuit number one and two, tube number (41) exhibited a value of (154) W. It is obvious that the tube at which the superheated mode occurs will sustain a small load capacity value. This explains why the superheat harms the efficiency of the cycle, because it has little benefit to the capacity and high effect towards increasing the compressor work.

Figure 6. Evaporator Load Distribution for Simulated Data at $T_{\text {in }}=36{ }^{\circ} \mathrm{C}$

Figure 6.a. Visual Representation of R-22 Results

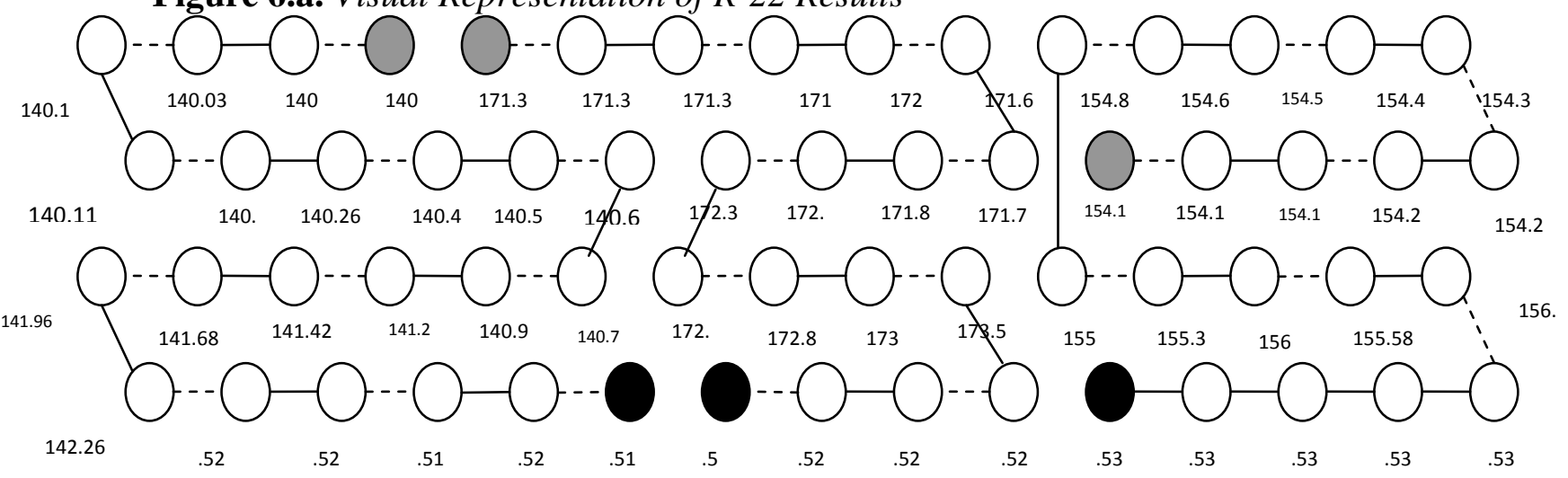

Figure 6.b. Visual Representation of $R-407 C$ Results

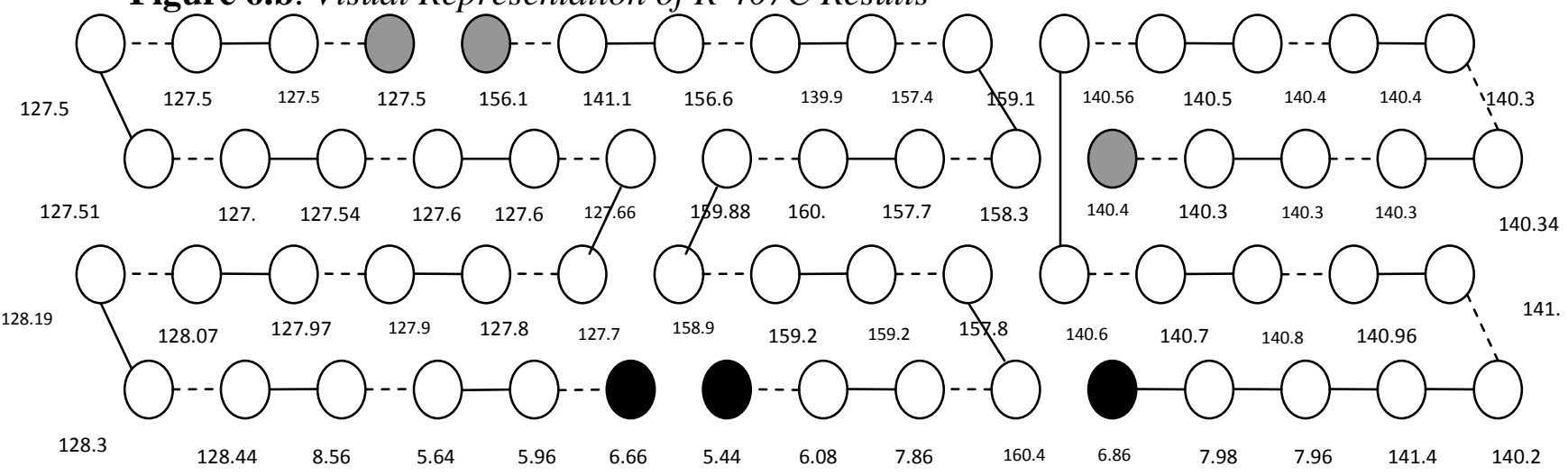

Figure 6.c. Visual Representation of R-407A Results

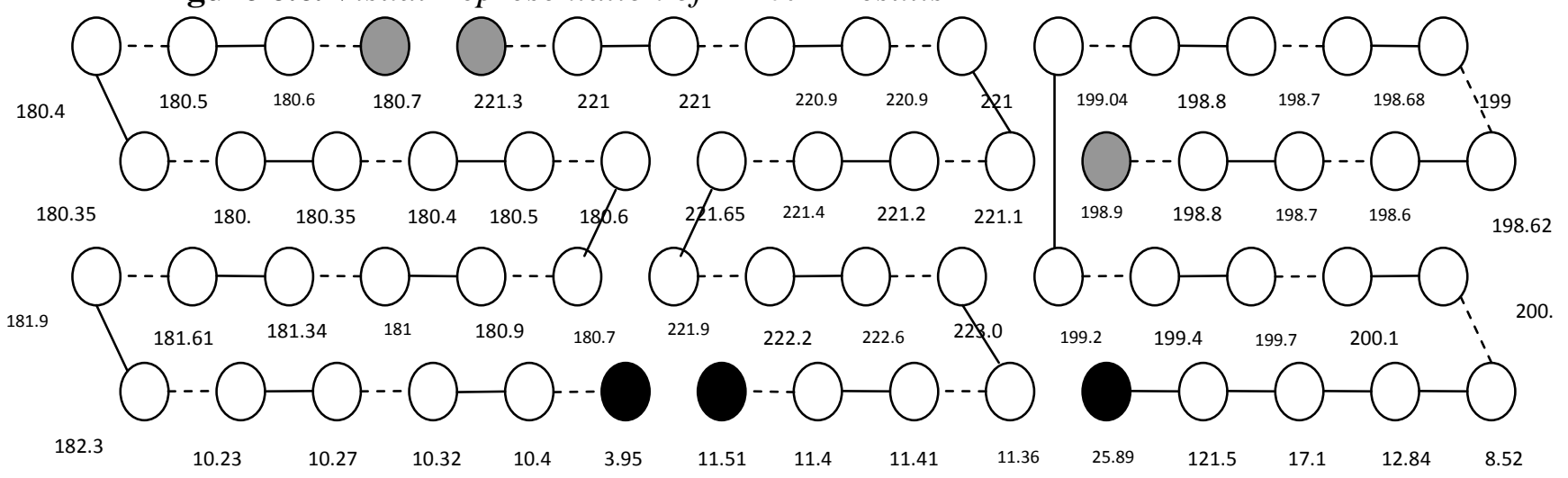


For R-407C, the cooling load distribution for each tube seems to be lower than that exists for R-22, but the collected value of cooling load distribution is higher than that of R-22. This is due to the number of tubes for R-407C that lies under two-phase condition is higher than that of R-22 due to less degree of superheat. Also, the value of load at superheated tube is higher than that of R22. Finally, the circuit effect shows the same behavior of R-22 result (the second circuit has the highest tube cooling capacity while the third circuit lies in between).

R-407A results show a significantly higher tube cooling capacity in the evaporation zone with value ranging between (180 to $223 \mathrm{~W})$. The same trend as those of the R-22 and R-407C circuit distribution is observed for R-407A. The value of the cooling capacity indicates that R-407A has a higher cooling capacity although it has a higher degree of superheat.

\section{Air Temperature Distribution}

Figure 7 shows the dry bulb temperature distribution of air past each tube exit. Here, for R-22 the temperature of air drops until reaches to almost $\left(16.9^{\circ} \mathrm{C}\right)$ in the first circuit, whereas it drops to a value of $\left(5^{\circ} \mathrm{C}\right)$ in the second and third circuit, Figure 7.a. The mean value of temperature for the three circuits is $\left(9.7^{\circ} \mathrm{C}\right)$, and the measured temperature is $\left(13^{\circ} \mathrm{C}\right)$ then the deviation becomes $(-25 \%)$. For R-407C the outlet air temperature value for three circuits falls within $\left(10.3-17.5^{\circ} \mathrm{C}\right)$ with mean value of $\left(15.7^{\circ} \mathrm{C}\right)$ which represent about $(-$ $1.8 \%$ ), Figure 7.b. For the case of R-407A, it records a remarkable drop in air temperature until reaches $\left(4.4^{\circ} \mathrm{C}\right)$ for the first and second circuit whereas the air temperature in the third circuit is almost equal to $\left(22.6^{\circ} \mathrm{C}\right)$, Figure $7 . c$. The mean value of the air temperature from the last row is $\left(10.3^{\circ} \mathrm{C}\right)$ which represents about (-24\%) deviation.

Figure 7. Evaporator Air Outlet Temperature Distribution at $T_{\text {air }}=36^{\circ} \mathrm{C}$

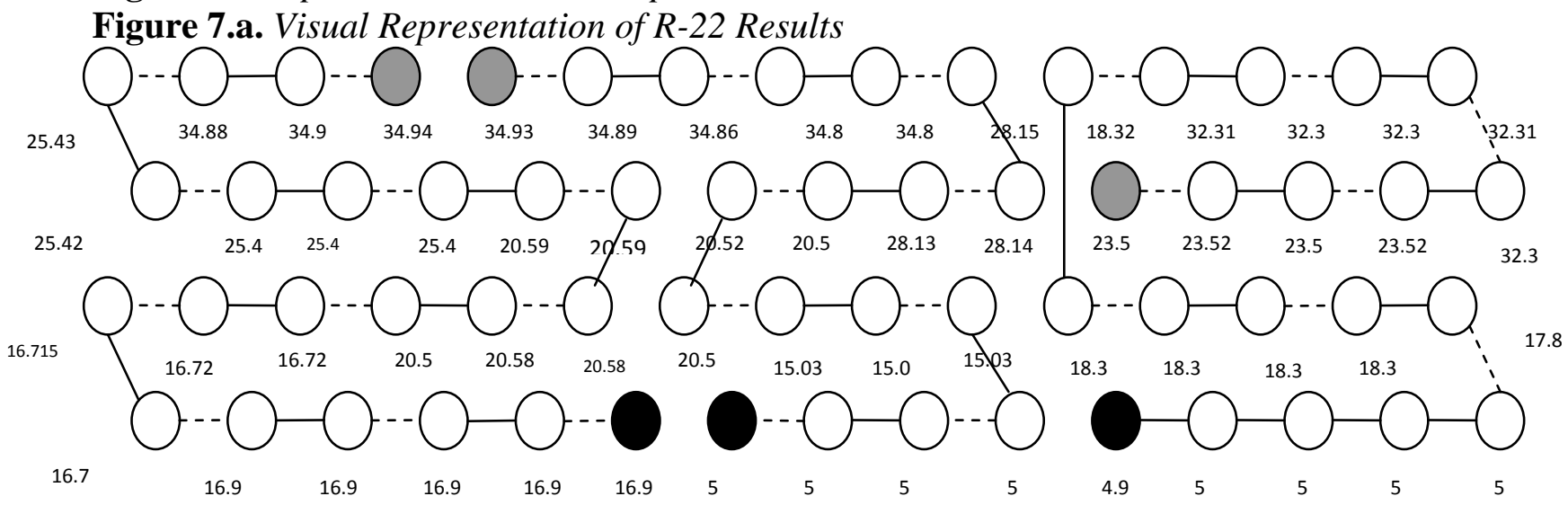


Figure 7.b. Visual Representation of $R-407 C$ Results

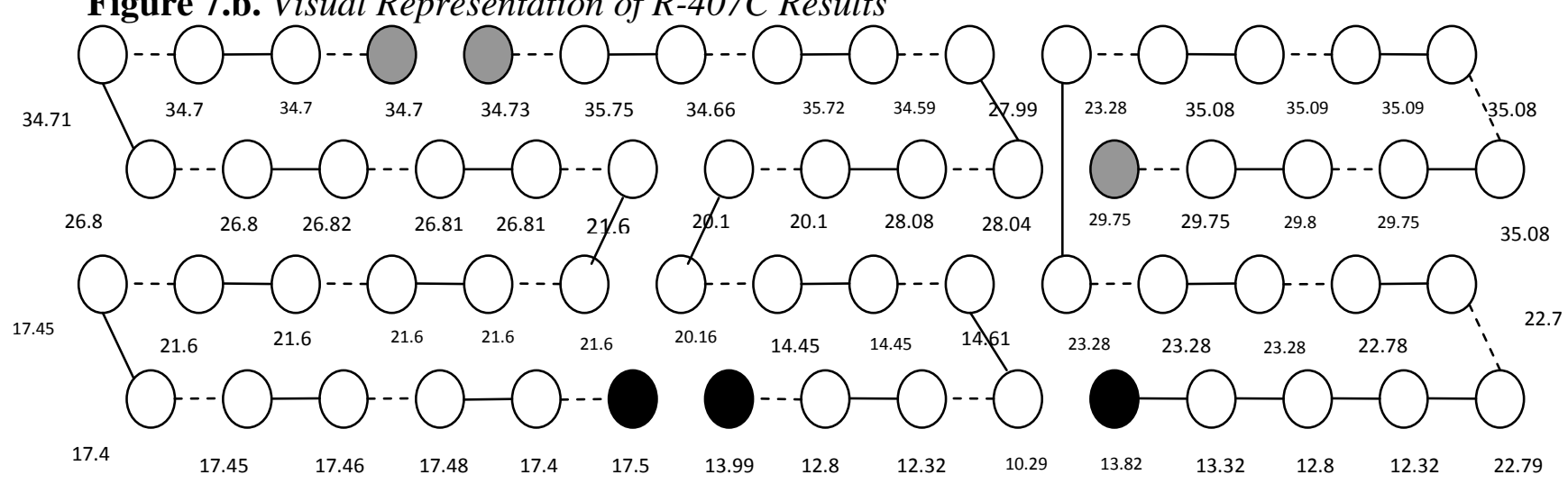

Figure 7.c. Visual Representation of R-407A Results

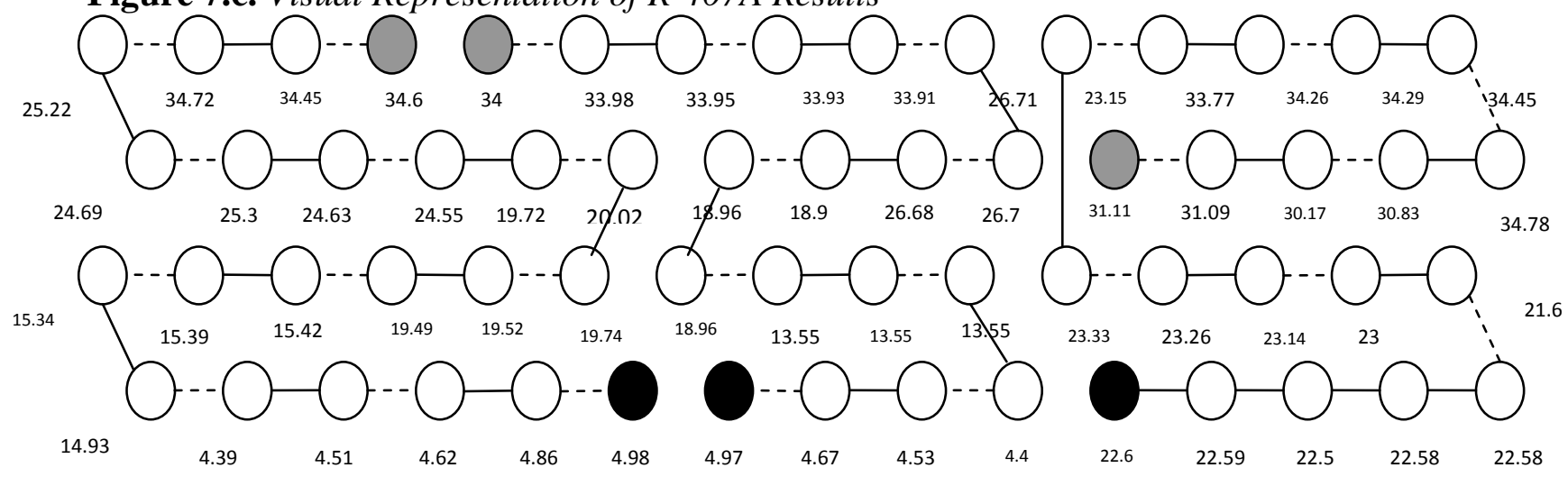

\section{Conclusions}

The following findings can be concluded from the present model established in this work:

- A mathematical numerical model was built; it was based on the "tube by tube" technique to simulate the experimental data of the finned tube evaporator collected from air conditioning unit.

- The evaporator duty is well simulated, the deviation between experimental and predicted values are ranged between $(-7 \%$ to 1 $\%)$ for all of the tested refrigerants.

- The predicted air dry bulb temperature showed a deviation from the experimental data with ranges between ( -25 to 12$) \%$ for R-22 and $( \pm 20) \%$ for R-407C and R-407A for all of the test air temperature range. 


\section{References}

Al-Nadawi, A. K. (2010) Experimental and Theoretical Study of R407C and R407A as Alternatives of R22 Refrigerant in a Window Type Air Conditioner. MSc. Thesis, Mechanical Engineering Department, College of Engineering, AlMustansiriya University.

Bensafi, A. and Borg, S. (1997) Design and simulation of finned-tube heat exchangers using pure and mixed refrigerants. Belgium, Proceedings of Clima 2000 conference, held in Burssels, p.1-24.

Berger E., Heimel M., Posch S., Almbauer R., and Elchinger M., (2014) Transcritical 1D Heat Exchanger Model for the Simulation of Domestic Cycles Working with R600a, $15^{\text {th }}$ International Refrigeration and Air Conditioning Conference, Perdue, p.1-11.

Choi, J. Y., Kedzierski M. A. and Domanski P. A. (1999) A Generalized Pressure Drop Correlation for Evaporation and Condensation of Alternative Refrigerants in Smooth and Micro-Fin Tubes. National Institute of Standards and Technology (NIST), Gaithersburg, USA.

Domanski, P. A. (1989) EVSIM An Evaporator Simulation Model Accounting for Refrigerant and One Dimensional Air Distribution. National Institute of Standards and Technology (NIST), Gaithersburg, USA.

Domanski, P. A. (1999) Finned-Tube Evaporator Model with a Visual Interface. International Congress of Refrigeration, National Institute of Standard and Technology (NIST), Sydney, Australia, p.19-24.

Domanski, P. A. and Didion, D. A. (1983) Computer Modeling of the Vapor Compression Cycle with Constant Flow Area Expansion Device. Center of Building Technology, National Bureau of Standards, Washington, USA.

Hassan, J. M., Tarrad A. H. and Abdullah, M. N. (2009) A dynamic modeling capability for subcritical vapor compression refrigeration system. Engineering and Technology Journal, 27 (13), p.2319-2338.

Incropera, F. P. and DeWitt, D. P. (1985) Fundamentals of Heat and Mass Transfer, $2^{\text {nd }}$ edition, USA: John Wiley \& Sons Inc.

Janna, W. S. (2000) Engineering Heat Transfer, $2^{\text {nd }}$ edition, USA: CRC press LLc.

Kempiak, M. J. and CrawFord, R. R. (1991) Three-Zone Modeling of a Mobile Air Conditioning Condenser. Air Conditioning and Refrigerating Center (ACRC), University of Illinois, Mechanical \& Industrial Engineering Department, Urbane.

Quiben, J. M . (2005) Experimental and Analytical Study of Two-Phase Pressure Drops during Evaporation in Horizontal Tubes. PhD thesis, DEA-Dynamique des Fluides et des Transferts, Universite Pierre et Mari Carie, Paris, France, Laussanne.

Radermacher, R. and Hwang, Y. (2005) Vapor Compression Heat Pumps With Refrigerant Mixtures, USA: Taylor \& Francis Group.

Sadler, E. M. (2000) Design Analysis of a Finned-Tube Condenser for a Residential Air Conditioner using R22. MSc thesis, The Academic Faculty, Georgia Institute of Technology.

Sarntichartsak P. and Kaewcholkram P. (2014) Investigation of appropriate refrigerant circuiting of fin-and-tube evaporator in an inverter air conditioner using ozonefriendly refrigerants as alternatives to $\mathrm{R} 22,5^{\text {th }}$ international conference on sustainable energy and environment Science, Technology and Innovation got ASEAN Green Growth, Bangkok, Thailand, p.247-250. 
Stewart, S. W. (2003) Enhanced Finned - Tube Condenser Design and Optimization. $\mathrm{PhD}$ thesis, The Academic Faculty, Georgia Institute of Technology.

Subbarao, P. M. V. (2008) Fin- Tube Condenser and Evaporator with Delta Winglet Window A/C, Mechanical Engineering Department, Indian Institute of Technology, Delhi, iitd.ac.in.

Sweeney, K. A. and Chato, J. C. (1996) The Heat Transfer and Pressure Drop Behavior of a Zeotropic Refrigerant Mixture in a Micro-Finned Tube. Air Conditioning and Refrigerating Center (ACRC), University of Illinois, Mechanical \& Industrial Engineering Department, Urbane.

Tarrad, A. H., Khudor, D. S. and Abdul Wahed, M. (2008) A simplified model for the prediction of the thermal performance for cross flow air cooled heat exchangers with a new air side thermal correlation. Engineering and Development Journal, 12 (3), p.1-28.

Tarrad, A. H. and Shehhab, U. S. (2007) The prediction of environment effect on the performance of a vapor compression refrigeration system in air conditioning application. Journal of Engineering and Development. 11 (1), p.169-189.

Techarungpaisan, P., Theerakulpisut S. and Priprem S. (2006) Modeling of a Split Type Air Conditioner with Integrated Water Heater. Khon Koen University, Faculty of Engineering, Mechanical Engineering Department, Thailand, p.12221237

\section{Nomenclatures}

A : The total surface area $\left(\mathrm{m}^{2}\right)$.

D: Tube diameter $(\mathrm{m})$.

f: Friction factor, function.

Fr: Froude number (dimensionless).

Fs: Fin spacing (m).

$\mathrm{g}$ : Gravitational acceleration $\left(\mathrm{m} / \mathrm{s}^{2}\right)$.

G: Mass flux $\left(\frac{\mathrm{kg}}{\mathrm{m}^{2} \cdot \mathrm{s}}\right)$.

$\mathrm{H}$ : Height of heat exchanger (m).

$\mathrm{j}$ : Colburne j-factor.

$\mathrm{k}$ :Thermal conductivity $\left(\frac{\mathrm{W}}{\mathrm{m} \cdot \mathrm{K}}\right)$.

$\mathrm{K}_{\mathrm{f}}$ : Two-phase number.

L: Flow length (Depth of the coil) (m).

$\mathrm{L}_{\mathrm{h}}$ : Louver height $(\mathrm{m})$.

$\mathrm{L}_{\mathrm{p}}$ : Louver pitch $(\mathrm{m})$.

$\dot{\mathrm{m}}$ : Mass flow rate $(\mathrm{kg} / \mathrm{s})$.

M: Molecular weight ( $\mathrm{kg} / \mathrm{mole})$.

$\mathrm{N}$ : Number of tubes.

$\mathrm{n}_{\mathrm{f}}$ : Number of fin.

$\mathrm{Nu}$ : Nusselt number (dimensionless).

P: Pressure (Mpa).

$\mathrm{P}_{\mathrm{r}}$ : Reduced pressure $\left(\mathrm{P} / \mathrm{P}_{\mathrm{c}}\right)$.

Pr: Prandle number (dimensionless).

$\mathrm{q}:$ Heat flux $\left(\mathrm{W} / \mathrm{m}^{2}\right)$

$\mathrm{R}$ : Gas constant. 
$\mathrm{r}_{\mathrm{e}}$ : Equivalent radius $(\mathrm{m})$.

Re: Reynolds number (dimensionless).

$\mathrm{Re}_{\mathrm{Dc}}$ : Reynolds number of the air based on collar diameter.

$\mathrm{R}^{\prime \prime}$ : Fouling factor $\left(\mathrm{m}^{2} . \mathrm{K} / \mathrm{W}\right)$.

$\mathrm{r}_{\mathrm{t}}$ : Outside tube radius $(\mathrm{m})$.

$\mathrm{R}_{\mathrm{w}}$ : Wall resistance $(\mathrm{K} / \mathrm{W})$.

St: Stanton number (dimensionless).

$\mathrm{T}_{\mathrm{b}}$ : Bubble point temperature $\left({ }^{\circ} \mathrm{C}\right)$.

$\mathrm{T}_{\mathrm{d}}$ : Dew point temperature $\left({ }^{\circ} \mathrm{C}\right)$.

$\mathrm{t}_{\mathrm{f}}$ : Fin thickness $(\mathrm{m})$.

$\mathrm{T}_{\text {int }}$ : Temperature at liquid-vapor interface.

$\mathrm{U}$ : Overall heat transfer coefficient $\left(\mathrm{W} / \mathrm{m}^{2} . \mathrm{K}\right)$.

$\mathrm{W}_{\mathrm{a}}$ : Humidity ratio ( $\mathrm{kg}$ of steam/ $\mathrm{kg}$ of dry air).

We: Weber number (dimensionless).

$\mathrm{X}$ : Mass fraction (quality) (dimensionless), concentration.

$\mathrm{X}_{\mathrm{l}}$ : Longitudinal (horizontal) tube spacing $(\mathrm{m})$.

$\mathrm{X}_{\mathrm{t}}$ : Transverse (vertical) tube spacing $(\mathrm{m})$.

$\mathrm{Z}$ : Number of row.

$Z_{g}$ : Ratio of the sensible cooling of the vapor to the cooling rate.

\section{Abbreviations: \\ EVATBT: Evaporator simulation using tube-by-tube method.}

\section{Subscripts:}

a: Air.

bc: Bulk convection contribution.

D: Diameter of the tube.

Dc: Collar diameter.

dew: Dew point temperature.

Di: Inner diameter.

e: Equivalent.

f,a: fouling air.

f,r: Fouling refrigerant.

f: Fin.

fg: Property difference between saturated vapor and saturated liquid.

fo: Fluid only.

g: gas, vapor.

Go: Gas only.

h,w: Hydraulic- diameter.

h: Homogenous, high

int: Interface.

1: Liquid.

Lo: Liquid only.

nb: nucleate pool boiling contribution 
r: reduced

s: Surface.

tf: Two-phase.

$\mathrm{v}$ : vapor.

w: Condensate water from the air

\section{Greek Symbols:}

$\bar{\alpha}$ : A single phase heat transfer coefficient $\left(\frac{\mathrm{W}}{\mathrm{m}^{2} \cdot \mathrm{K}}\right)$.

$\phi_{\mathrm{fo}}^{2}$ : Two-phase multiplier.

$\Phi^{\mp}$ : Percentage deviation (\%).

$\Delta \mathrm{h}$ : Enthalpy change of the mixture.

$\Delta \mathrm{T}$ : Temperature glide $\left({ }^{\circ} \mathrm{C}\right)$, Temperature difference.

$\propto$ : Heat transfer coefficient $\left(\frac{\mathrm{W}}{\mathrm{m}^{2} \cdot \mathrm{K}}\right)$.

$\epsilon$ : Void fraction (dimensionless).

$\eta$ : Efficiency.

$\mu$ : Viscosity $\left(\frac{\mathrm{kg}}{\mathrm{m} \cdot \mathrm{s}}\right)$.

$\rho$ : Density $\left(\frac{\mathrm{kg}}{\mathrm{m}^{3}}\right)$.

$\mathrm{v}$ : Specific volume $\left(\frac{\mathrm{m}^{3}}{\mathrm{~kg}}\right)$.

$\theta$ : The angle that the wave forms has been shift.

$\sigma:$ Surface tension $\left(\frac{\mathrm{N}}{\mathrm{m}}\right)$. 
